\title{
Bandwidth and Gain Improvement of a Circularly Polarized Dual-Rhombic Loop Antenna
}

\author{
RongLin Li, Senior Member, IEEE, Anya Traille, Joy Laskar, Fellow, IEEE, and \\ Manos M. Tentzeris, Senior Member, IEEE
}

\begin{abstract}
In this letter, we present a novel way to improve the performance of a circularly polarized (CP) dual-rhombic loop antenna. The bandwidth is enhanced by adding a pair of parasitic rhombic loops inside the dual-rhombic loop while the gain is increased with the help of a short backfire antenna (SBA). Good impedance matching is obtained by introducing a broadband balun. The addition of the parasitic elements leads to a bandwidth of $46 \%$ for axial ratio (AR) $\leq 2 \mathrm{~dB}$ with an impedance bandwidth of $50 \%$ for VSWR $\lesseqgtr 2$. The dual-rhombic loop excited SBA achieves an $A R(\leq 3 \mathrm{~dB})$ bandwidth of $45 \%$ with an antenna gain of $11 \mathrm{dBi}$.
\end{abstract}

Index Terms-Broadband antenna, circular polarization, impedance matching, loop antenna, short backfire antenna (SBA).

\section{INTRODUCTION}

$\mathbf{I}^{1}$ $\mathrm{T}$ is well known that the most commonly used broadband planar circularly polarized $(\mathrm{CP})$ radiating element is the spiral antenna [1]. However, when a spiral antenna is backed by a conducting planar reflector (i.e., a ground plane) for unidirectional radiation, its broadband performance can be significantly deteriorated. It was demonstrated in [2] that the bandwidth for an axial ratio (AR) of less than $3 \mathrm{~dB}$ of an Archimedean spiral antenna in the presence of a conducting reflector was less than 20\%. About seven years ago, it was found that a dual-rhombic loop can also serve as a broadband CP antenna [3], [4]. A bandwidth of $20 \%$ for $\mathrm{AR} \leq 2 \mathrm{~dB}$ was obtained for the dual-rhombic loop antenna.

In this letter, we further improve the bandwidth of the dual-rhombic loop by adding a pair of parasitic rhombic loops inside the original loop. The impedance matching of the broadband CP antenna is achieved by incorporating a broadband balun into the feeding structure. The gain of the dual-rhombic loop antenna is enhanced by employing it as the excitation element of a short backfire antenna (SBA).

\section{BANDWIDTH IMPROVEMENT}

The configuration of a CP dual-rhombic loop antenna is shown in Fig. 1. The square $\left(\mathrm{W}_{1} \times \mathrm{W}_{1}\right)$ dual-rhombic loop is printed on a thin square $\left(\mathrm{L}_{\mathrm{S}} \times \mathrm{L}_{\mathrm{S}}\right)$ dielectric substrate (substrate thickness $=0.254 \mathrm{~mm}$ ) with a low dielectric

Manuscript received September 27, 2005; revised January 10, 2006. This work was supported by the Georgia Electronic Design Center, NSF Career Award \#9964761, NSF Grant ECS-0313951, and the NSF PRC of Georgia Tech.

The authors are with the School of Electrical and Computer Engineering, Georgia Institute of Technology, Atlanta, GA 30332 USA (e-mail: rlli@ece.gatech.edu).

Digital Object Identifier 10.1109/LAWP.2006.872428

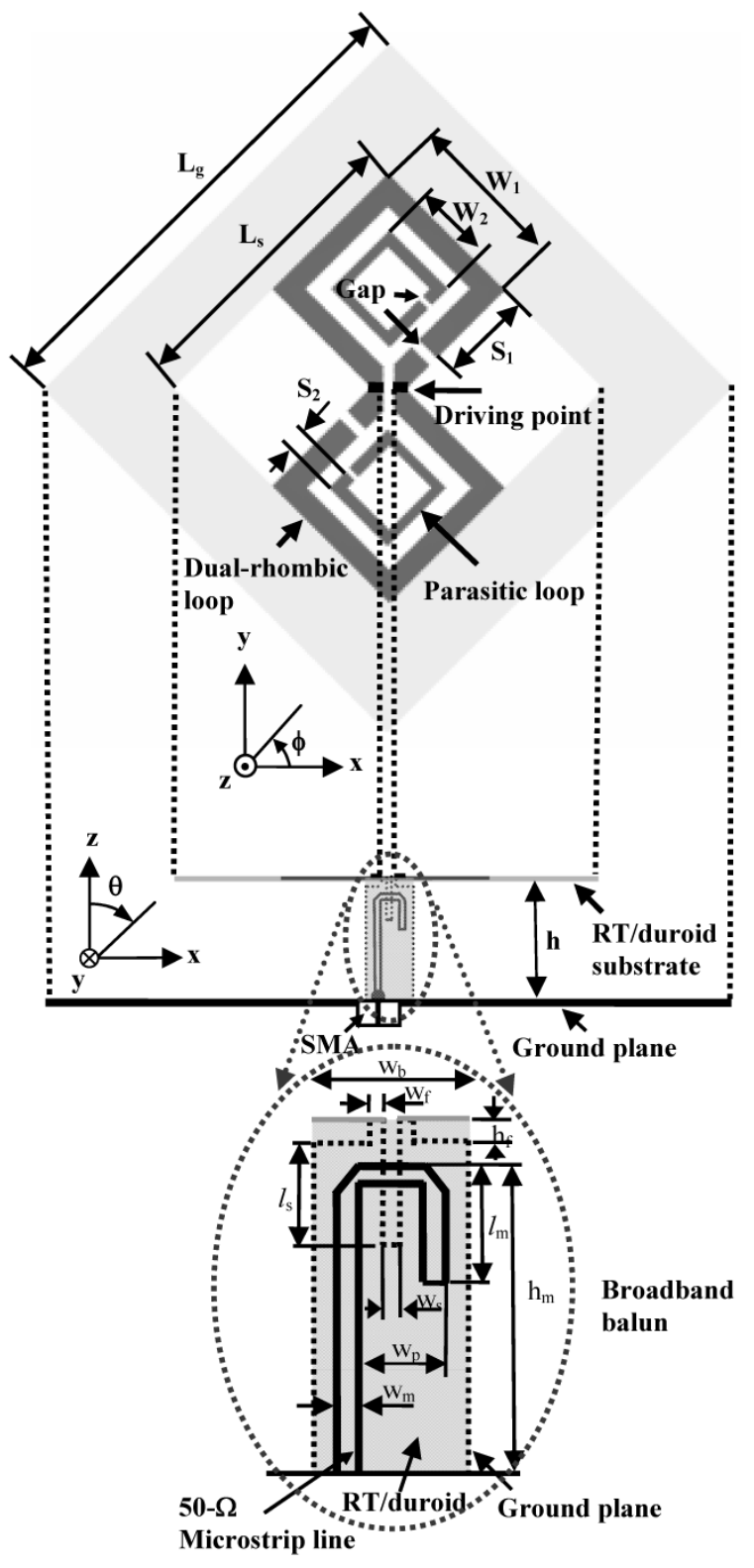

Fig. 1. Broadband circularly polarized dual-rhombic loop antenna with impedance matching. (The strip widths of the dual-rhombic loop and of the parasitic loops are 2.4 and $1.2 \mathrm{~mm}$, respectively; the gap widths on the dual-rhombic loop and on the parasitic loops are 1 and $0.5 \mathrm{~mm}$, respectively; $\mathrm{L}_{\mathrm{g}}=50 \mathrm{~mm}, \mathrm{~L}_{\mathrm{s}}=31.2 \mathrm{~mm}, \mathrm{w}_{\mathrm{b}}=6.0 \mathrm{~mm}, \mathrm{w}_{\mathrm{f}}=0.6 \mathrm{~mm}$, $\mathrm{w}_{\mathrm{s}}=0.5 \mathrm{~mm}, \mathrm{w}_{\mathrm{m}}=0.8 \mathrm{~mm}, \mathrm{w}_{\mathrm{p}}=3.2 \mathrm{~mm}, \mathrm{~h}_{\mathrm{f}}=1.0 \mathrm{~mm}$, $\mathrm{h}_{\mathrm{m}}=14 \mathrm{~mm}, l_{\mathrm{s}}=3.5 \mathrm{~mm}, l_{\mathrm{m}}=4 \mathrm{~mm}$.).

constant (RT/duroid 5880, $\varepsilon_{\mathrm{r}}=2.2$ ). To radiate a CP wave, a pair of small gaps is introduced on the dual-rhombic loop. A 


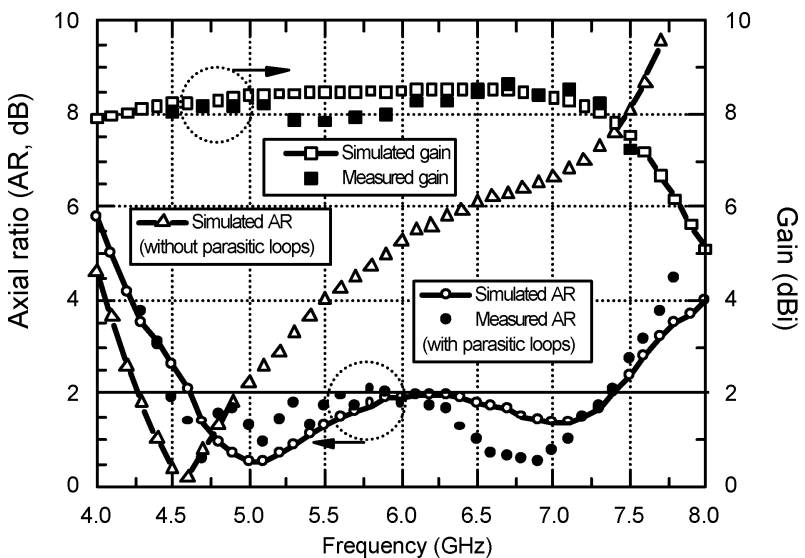

Fig. 2. Simulated and measured results for axial ratio and gain of the broadband circularly polarized dual-rhombic loop antenna.

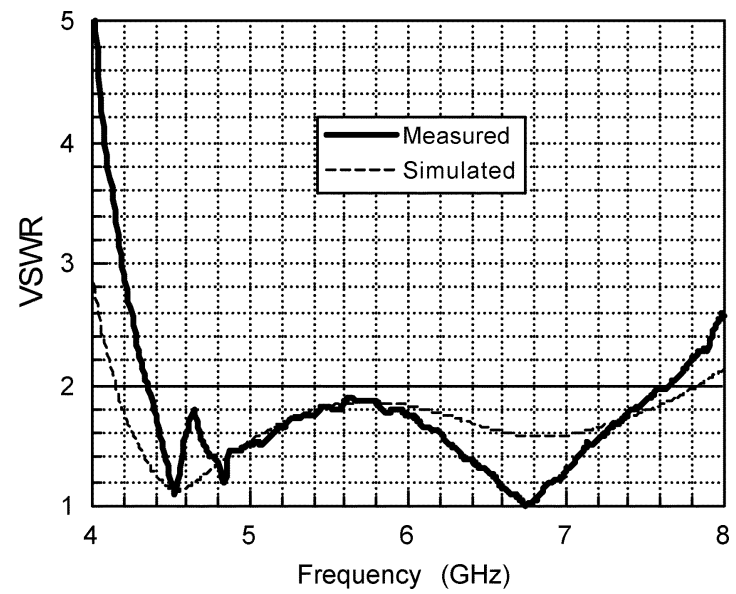

Fig. 3. VSWR of the broadband circularly polarized dual-rhombic loop antenna with impedance matching.

pair of square $\left(\mathrm{W}_{2} \times \mathrm{W}_{2}\right)$ parasitic rhombic loops (also with a small gap) is added inside the dual-rhombic loop for bandwidth enhancement. An important feature of this loop antenna is that the sense of circular polarization may be adjusted by changing the positions of the small gaps on the loops using RF switches such as microelectromechanical systems or p-i-n diodes. The $\mathrm{CP}$ rhombic loop is driven at its center by a broadband balun, which was also fabricated on the same type of RT/duroid 5880 substrate. This kind of broadband balun has been widely used to excite a dipole antenna [5]. The broadband balun can excite the balanced mode by making use of the coupling between the microstrip line printed on one side of the substrate to the slot which is etched on the other side (it also serves as the ground plane for the microstrip line) of the substrate. A good impedance matching can be achieved by adjusting the length $\left(l_{\mathrm{s}}\right)$ of the slot, the height $\left(\mathrm{h}_{\mathrm{m}}\right)$ and the length $\left(l_{\mathrm{m}}\right)$ of the microstrip line. The printed CP dual-rhombic loop is backed by a square $\left(\mathrm{L}_{\mathrm{g}} \times \mathrm{L}_{\mathrm{g}}\right)$ copper plate (i.e., a ground plane) at a height $h$ for unidirectional radiation and fed through an SMA connector.

We designed and fabricated a broadband $\mathrm{CP}$ dual-rhombic loop antenna for operating at C-band (4-8 GHz). The antenna was initially designed using NEC 1.1, and optimized by a full-
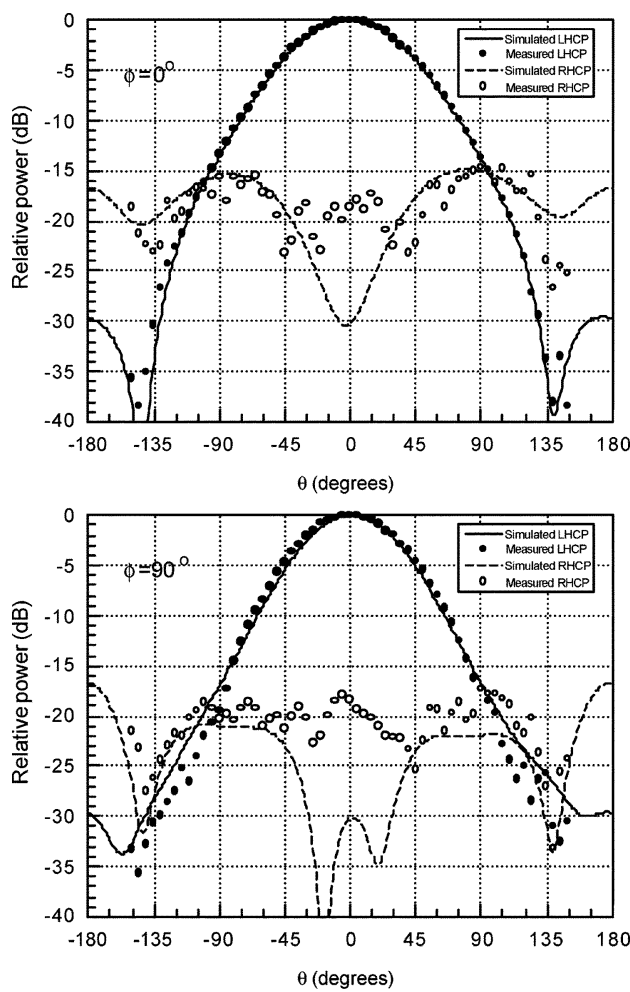

Fig. 4. Radiation patterns of the broadband circularly polarized dual-rhombic loop antenna $(\mathrm{LHCP}=$ Left-hand circular polarization and RHCP $=$ Right-hand circular polarization) at $5 \mathrm{GHz}$.
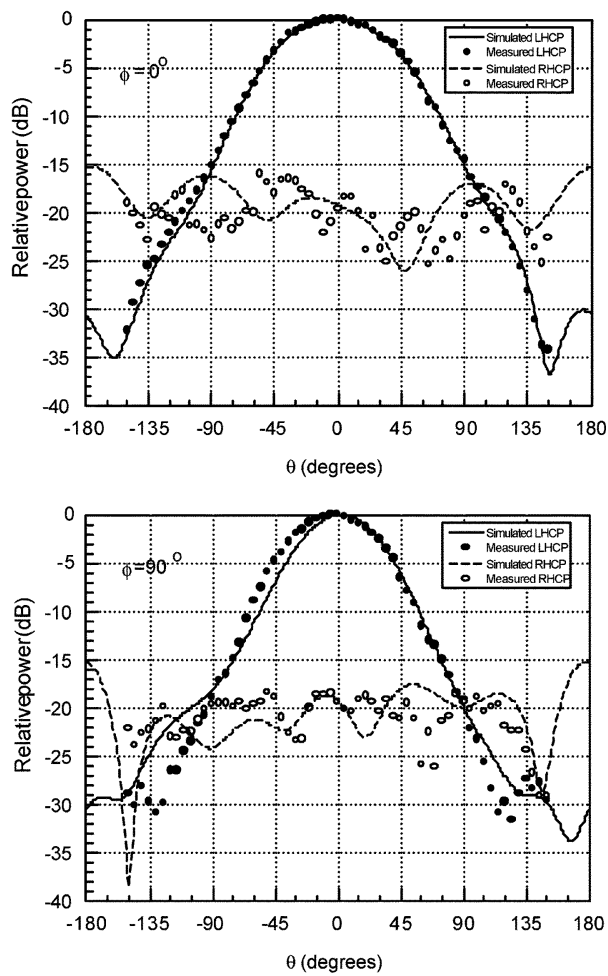

Fig. 5. Radiation patterns of the broadband circularly polarized dual-rhombic loop antenna ( $\mathrm{LHCP}=$ Left-hand circular polarization and RHCP = Right-hand circular polarization) at $6 \mathrm{GHz}$.

wave design tool-Microstripes 6.5. By adjusting the loop dimensions (i.e., $\mathrm{W}_{1}$ and $\mathrm{W}_{2}$ ), the gap positions (i.e., $\mathrm{S}_{1}$ and $\mathrm{S}_{2}$ ), 

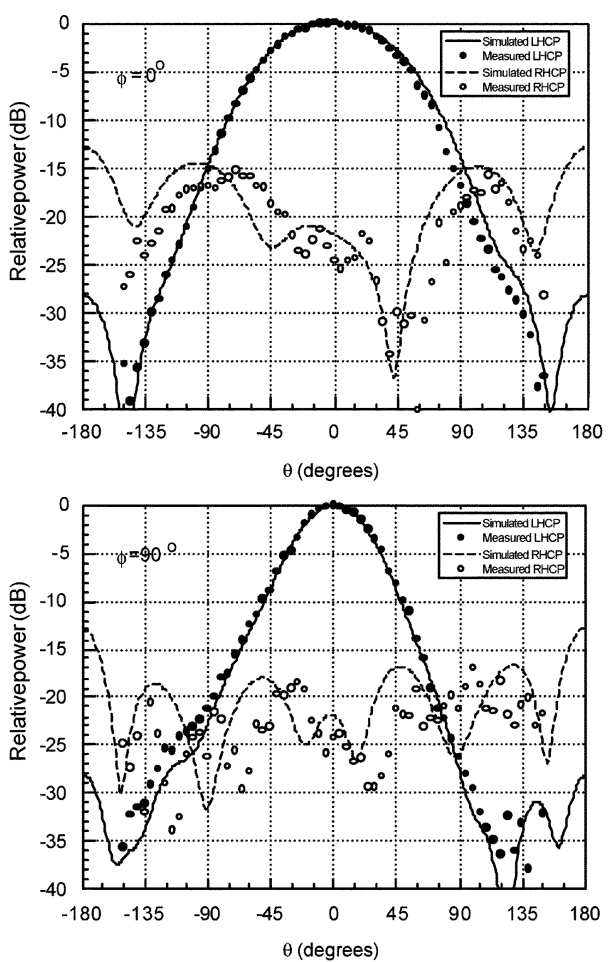

Fig. 6. Radiation patterns of the broadband circularly polarized dual-rhombic loop antenna (LHCP = Left-hand circular polarization and RHCP = Right-hand circular polarization) at $7 \mathrm{GHz}$.

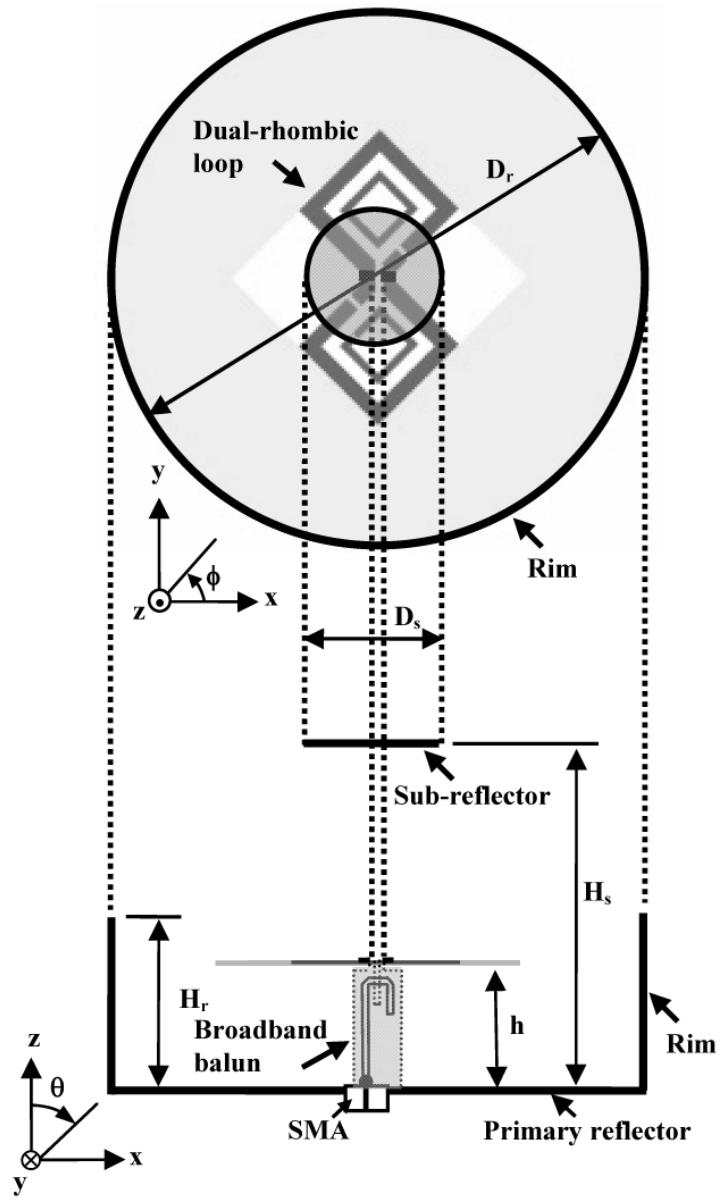

Fig. 7. SBA excited by a dual-rhombic loop.

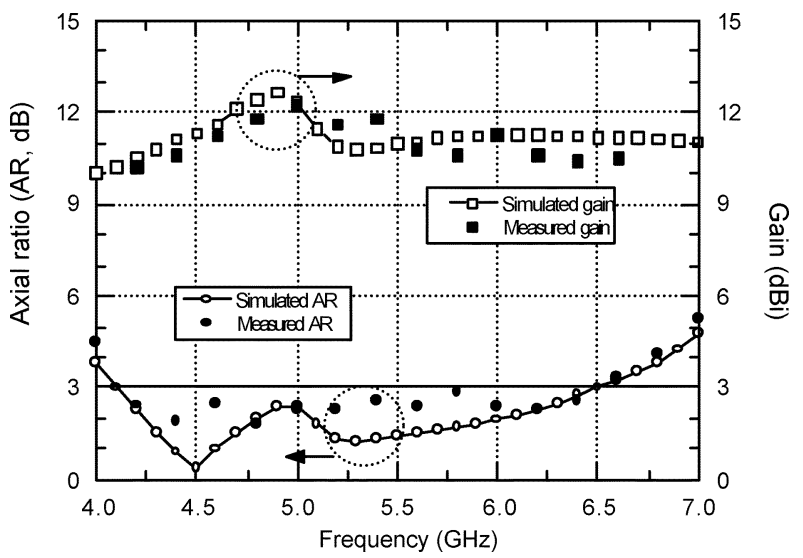

Fig. 8. Simulated and measured results for axial ratio and gain of the dual-rhombic loop excited SBA.

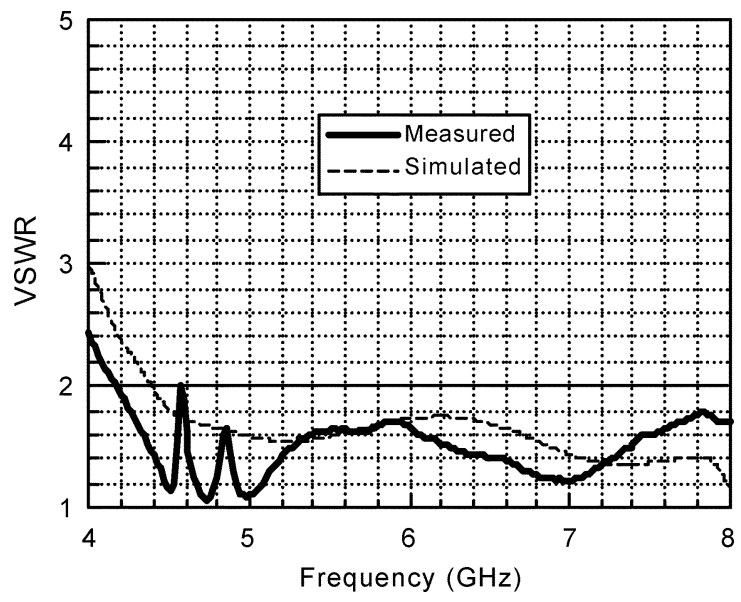

Fig. 9. VSWR of the dual-rhombic loop excited SBA.

and the height $h$, a broadband performance for circular polarization can be achieved. By simulation, the optimized geometrical parameters for the $\mathrm{CP}$ dual-rhombic loop antenna were found to be $\mathrm{W}_{1}=16.8 \mathrm{~mm}, \mathrm{~W}_{2}=8.4 \mathrm{~mm}, \mathrm{~S}_{1}=9.9 \mathrm{~mm}$, $\mathrm{S}_{2}=2.2 \mathrm{~mm}$, and $h=16 \mathrm{~mm}$. The geometrical parameters optimized for the broadband balun are included in Fig. 1.

Fig. 2 shows the simulated and measured results for the on-axis (in the $\mathrm{z}$ direction) $\mathrm{AR}$ and gain of the broadband $\mathrm{CP}$ rectangular loop antenna. It is found that the bandwidth for $\mathrm{AR} \leq 2 \mathrm{~dB}$ of the dual-rhombic loop antenna with parasitic loops is about $46 \%$. For comparison, the simulated AR for the dual-rhombic loop antenna without the parasitic loops is also plotted in this figure, which shows a 2-dB AR bandwidth of only $15 \%$. Obviously, the parasitic loops play an important role for the bandwidth enhancement. The reason for this effect is that the dual-rhombic loop can only create one minimum AR point while the parasitic loops can produce an additional minimum AR point. An appropriate combination of the two minimum AR points leads to a significant enhancement for the CP bandwidth. The gain of the antenna maintains a value around $8 \mathrm{dBi}$ over the $2-\mathrm{dB}$ AR bandwidth. The simulated and measured results for the voltage standing-wave ratio (VSWR) are presented in Fig. 3. The bandwidth for VSWR $\leq 2$ is about $50 \%$, entirely covering the $\mathrm{AR} \leq 2 \mathrm{~dB}$ bandwidth. 

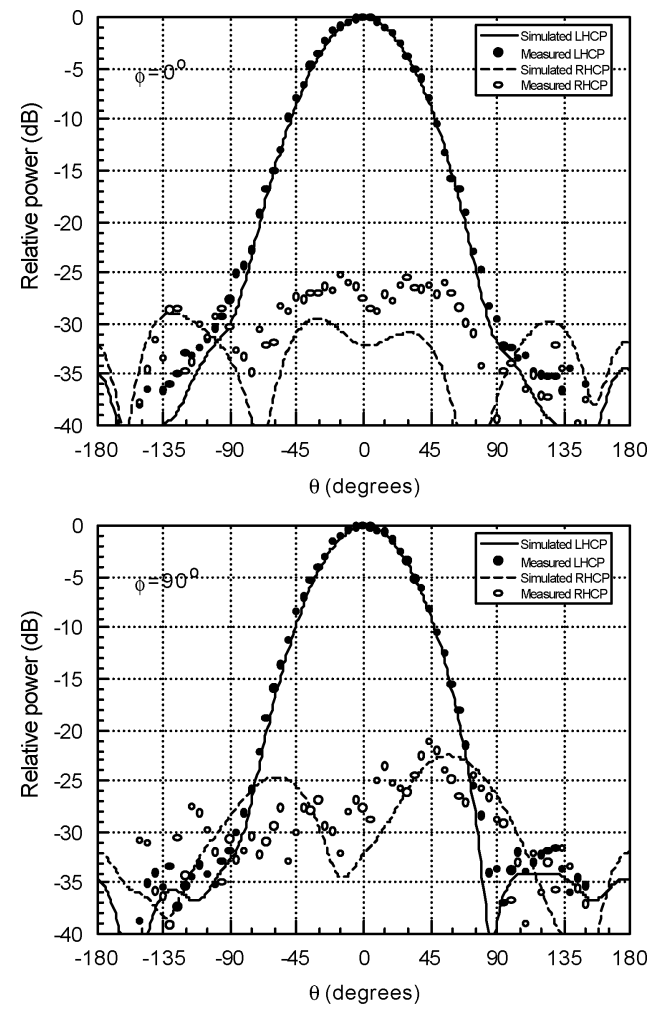

(a)
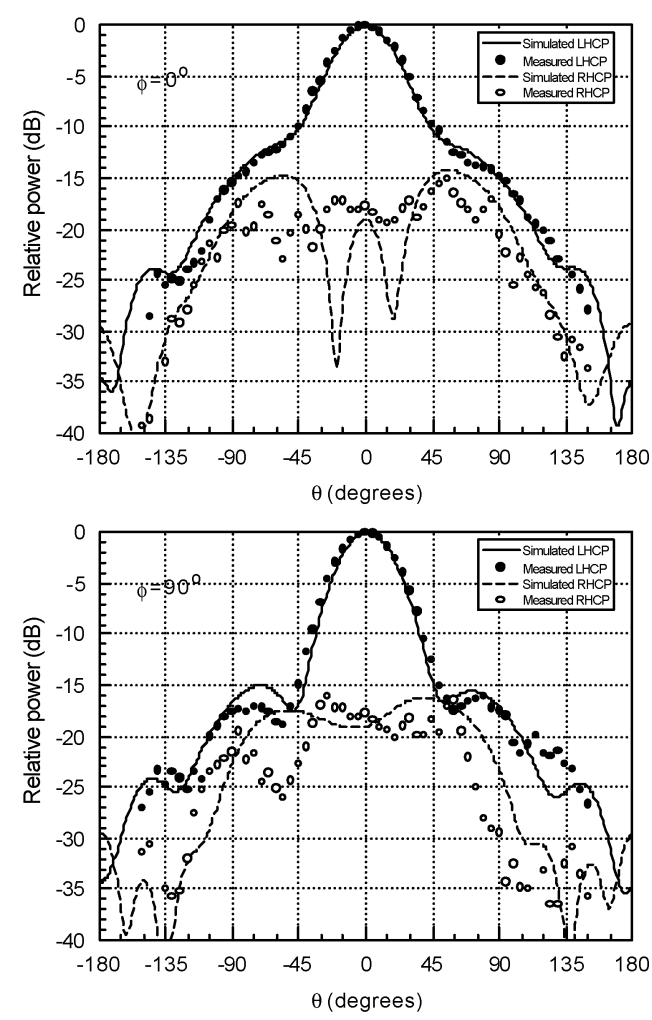

(b)

Fig. 10. Radiation patterns of the dual-rhombic loop excited SBA at (a) $4.5 \mathrm{GHz}$ and (b) $6 \mathrm{GHz}$.

Figs. 4-6 show the radiation patterns simulated and measured in the principle planes $\left(\phi=0^{\circ}\right.$ and $\phi=90^{\circ}$ planes $)$ at 5,6 , and $7 \mathrm{GHz}$. Good agreement is observed between the simulated and measured results. No significant change is observed for the radiation patterns over the $2-\mathrm{dB}$ AR bandwidth. As expected, the beamwidth in the $\phi=0^{\circ}$ plane is wider than that in the $\phi=90^{\circ}$ plane because the dimension of the dual-rhombic loop in the $\mathrm{y}$ direction is much longer than that in the $\mathrm{x}$ direction.

\section{GAIN ENHANCEMENT}

The gain of the broadband CP dual-rhombic loop antenna can be enhanced by introducing it in a configuration of the SBA [6]. The dual-rhombic loop now serves as an excitation element of the SBA, as illustrated in Fig. 7. The SBA has a primary reflector $\left(\mathrm{D}_{\mathrm{r}}\right.$ in diameter), a subreflector $\left(\mathrm{D}_{\mathrm{s}}\right)$, and a rim. The heights of the subreflector and the rim are $\mathrm{H}_{\mathrm{s}}$ and $\mathrm{H}_{\mathrm{r}}$, respectively. The subreflector is supported by a Styrofoam pole. The dimensions of two reflectors and the rim were optimized for a maximum gain while keeping the broadband performance for circular polarization. The optimal sizes are: $\mathrm{D}_{\mathrm{r}}=80 \mathrm{~mm}, \mathrm{D}_{\mathrm{s}}=20 \mathrm{~mm}$, $\mathrm{H}_{\mathrm{r}}=20 \mathrm{~mm}$, and $\mathrm{H}_{\mathrm{s}}=45 \mathrm{~mm}$.

Fig. 8 shows the simulated and measured results for the AR and gain of the dual-rhombic loop excited SBA. The AR level (in $\mathrm{dB}$ ) is slightly increased by the subreflector and the rim, but it still demonstrates a broadband feature. The bandwidth for $\mathrm{AR} \leq 3 \mathrm{~dB}$ is found to be $45 \%$ while the gain is around $11 \mathrm{dBi}$, $3 \mathrm{~dB}$ higher than the dual-rhombic loop. The simulated and measured results for VSWR are presented in Fig. 9, retaining a broadband performance. The radiation patterns simulated and measured at 4.5 and $6 \mathrm{GHz}$ are plotted in Fig. 10. The SBA has a more symmetrical radiation pattern and a lower backside level than the dual-rhombic loop.

\section{CONCLUSION}

The bandwidth of a CP dual-rhombic loop antenna can be significantly enhanced by adding a pair of parasitic loops inside the original loop while its gain can be increased by introduction of the configuration of a SBA. Good impedance matching is realized by incorporating a broadband balun into the CP loop antenna. The CP dual-rhombic loop antenna achieves a 2-dB AR bandwidth of $46 \%$ with a $50 \%$ bandwidth for VSWR $\leq 2$. The dual-rhombic loop excited SBA can increase the antenna gain by $3 \mathrm{~dB}$ while maintaining a broadband performance for circular polarization and impedance matching.

\section{REFERENCES}

[1] W. L. Curtis, "Spiral antennas," IEEE Trans. Antennas Propag., vol. 8, no. 3, pp. 298-306, May 1960.

[2] H. Nakano, K. Nogami, S. Arai, H. Mimaki, and J. Yamauchi, "A spiral antenna backed by a conducting plane reflector," IEEE Trans. Antennas Propag., vol. 34, no. 6, pp. 791-796, Jun. 1986.

[3] H. Morishita, K. Hirasawa, and T. Nagao, "Circularly polarized wire antenna with a dual rhombic loop," Proc. Inst. Elect. Eng. Microw. Antennas Propag., vol. 145, no. 3, pp. 219-224, Jun. 1998.

[4] H. Morishita, H. Hamada, K. Nishida, and T. Nagao, "A wideband circularly polarized dipole antenna," in Proc. IEEE Antennas and Propagation Society Int. Symp., Atlanta, GA, 1998, pp. 2348-2350.

[5] B. Edward and D. Rees, "A broadband printed dipole with integrated balun," Microw. J., no. 5, pp. 339-344, 1987.

[6] H. W. Ehrenspeck, "The short-backfire antenna," Proc. IEEE, vol. 53, no. 8, pp. $1138-1140$, Aug. 1965. 